\title{
Coulisses
}

Revue de théâtre

\section{Figaro divorce à la Comédie Française}

Ödön von Horváth, Figaro divorce. Mise en scène de Jacques Lassalle

\section{Philippe Baron}

\section{OpenEdition}

\section{Journals}

Édition électronique

URL : https://journals.openedition.org/coulisses/959

DOI : $10.4000 /$ coulisses.959

ISSN : 2546-9460

Éditeur

Presses universitaires de Franche-Comté

\section{Édition imprimée}

Date de publication : 31 décembre 2009

Pagination : 25-27

ISBN : 978-2-84867-270-0

ISSN : $1150-594 \mathrm{X}$

Référence électronique

Philippe Baron, « Figaro divorce à la Comédie Française », Coulisses [En ligne], 39 | Automne 2009, mis en ligne le 30 novembre 2016, consulté le 29 décembre 2022. URL : http://journals.openedition.org/ coulisses/959; DOI : https://doi.org/10.4000/coulisses.959

Ce document a été généré automatiquement le 29 décembre 2022.

Tous droits réservés 


\title{
Figaro divorce à la Comédie Française
}

\author{
Ödön von Horváth, Figaro divorce. Mise en scène de Jacques Lassalle \\ Philippe Baron
}

\section{RÉFÉRENCE}

Ödön von Horváth, Figaro divorce. Mise en scène : Jacques Lassalle. La Comédie-Française

1 La Comédie-Française vient de reprendre une pièce de l'écrivain austro-hongrois, Ödön von Horváth ${ }^{1}$, Figaro divorce. Celui-ci a fui le nazisme en 1933 et a été victime d'un accident mortel à Paris en 1938.

2 Figaro divorce est une suite du Mariage de Figaro de Beaumarchais. Les personnages principaux sont les mêmes et Horváth, pour souligner la continuité des deux pièces, insère dans l'acte I (tableau 2) quelques phrases du célèbre monologue de l'acte V. Il imagine que la Révolution de 1789 a éclaté. Le comte et la comtesse, Figaro et Suzanne passent clandestinement la frontière et se réfugient dans une région qui pourrait être la Bavière. Le comte est le type de l'émigré qui n'a rien appris ni rien oublié. Il supporte mal d'être privé de ses privilèges et il est persuadé que l'Ancien régime va être rétabli d'un jour à l'autre. Figaro, plus lucide, s'amuse de la naïveté de son maître. Le comte vend les derniers bijoux de la comtesse, perd au jeu l'argent qu'il en a retiré et après avoir habité de grands hôtels est obligé de se contenter d'une modeste chambre meublée. Il finit par être compromis dans une affaire immobilière. Figaro retourne à son ancien métier de barbier et ouvre un salon de coiffure. De graves désaccords éclatent entre lui et Suzanne ; elle est très déçue parce que, à cause de l'incertitude de leur situation, il ne veut pas avoir un enfant et elle trouve que, pour conserver sa clientèle, il flatte beaucoup les gens du lieu. Exaspérée, elle le trompe et divorce sans se sentir tout à fait détachée de lui. Elle travaille un moment dans un bar tenu par Chérubin qui s'est beaucoup empâté. On apprend plus tard que la comtesse est morte de maladie. Figaro revient en France où la Révolution a abouti à l'installation d'un régime autoritaire qui pourrait être le stalinisme mais qui ici, compte tenu des 
circonstances, est évidemment le nazisme. Le château d'Almaviva a été converti en un centre d'éducation pour la jeunesse.

3 Pédrille, le piqueur du comte, prend ici une importance qu'il n'avait pas dans la pièce de Beaumarchais ; il en est devenu l'intendant et il tient des discours hitlériens : il affirme qu'une nouvelle race doit naître et que l'individu doit se sacrifier à la collectivité. Figaro, qui ne pense plus qu'à ses intérêts, s'arrange pour prendre sa place. Des jeunes gens armés qui rappellent les chemises brunes de $\mathrm{Röhm}^{2}$ patrouillent. Suzanne et le comte reviennent.

Suzanne se réconcilie avec Figaro qu'elle n'a pas cessé d'aimer. Les jeunes gens veulent fusiller le comte mais Figaro obtient qu'ils le laissent en liberté ; ils vont casser des vitres comme si Horváth avait pressenti en 1936 la Nuit de cristal de $1938^{3}$. La révolution, dit-il, triomphe lorsqu'on n'a plus besoin de frapper ses ennemis.

La pièce, qui est souvent amusante, évoque les difficultés de la vie des émigrés et raille le nazisme. Figaro n'est cependant plus le gaillard à l'esprit libre de Beaumarchais ; il devient de plus en plus opportuniste et, même s'il sauve le comte, il s'adapte à un régime qui bafoue les droits de l'Homme. Il est sans doute difficile sous une dictature de survivre sans se compromettre.

6 La pièce est mise en scène par Jacques Lassalle qui s'est permis parfois de modifier légèrement le texte d'Horváth ${ }^{4}$. Deux décors sont constitués par des toiles peintes. Le premier représente un ciel d'orage nocturne et ressemble beaucoup à un tableau du peintre expressionniste, Emil Nolde. Le deuxième décor de ce genre représente un paysage de neige car, avant la ruine du comte, la comtesse s'adonne aux joies du patinage. Jacques Lassalle utilise ensuite une scène tournante qui permet des changements de lieux très rapides ; on voit successivement un salon de coiffure, une chambre meublée, une chambre d'auberge, un bureau d'aide aux réfugiés et le bar de Chérubin.

7 L'interprétation est excellente. Bruno Raffaelli est un comte Almaviva avantageux et sûr de lui, et Michel Vuillermoz un Figaro trop malin pour être honnête ; Denis Podalydès rend à merveille le fanatisme et la sottise de Pédrille. Florence Viala et Clotilde de Bayser font bien sentir, l'une, la mélancolie de la comtesse, l'autre, les sentiments contradictoires de Suzanne.

Il est toujours difficile de donner une suite à une belle pièce. Beaumarchais et Horváth ont repris dans La Mère coupable et Figaro divorce les personnages du Mariage mais Beaumarchais n'a écrit qu'un drame bourgeois assez terne et c'est paradoxalement un écrivain étranger qui a tiré le meilleur parti de son chef-d'œuvre.

\section{NOTES}

1. . Florence Baillret, Ödön von Horváth, Belin 2008.

2. . Les "chemises brunes" étaient les membres de la SA (Sturmabteilung, section d'assaut), milice d'Hitler dirigée par Röhm. Röhm entra en conflit avec Hitler. Hitler le fit arrêter et fusiller 
ainsi que son état-major dans la nuit du 29 au 30 juin 1934, dite « Nuit des long couteaux ». La SA fut évincé par la SS (Schutzstaffel, unité de protection) qui commit de nombreux crimes.

3. . La nuit du 9 au 10 novembre 1938 est appelée Nuit de Cristal parce que les nazis cassèrent pendant cette nuit les vitrines de magasins appartenant à des juifs. Ils commirent de nombreuses exactions et brûlèrent des synagogues.

4. . Il attribue à Pédrille le discours nazi que Figaro prononce à l'acte III. 